\title{
Breathing with an enemy in the kitchen: a narrative review of the concepts on cleaner energy, respiratory effects of indoor air pollution due to cooking and the potential way forward
}

\author{
PKB Mahesh ${ }^{1 *}$, MW Gunathunga ${ }^{2}$, S Jayasinghe ${ }^{3}$, SM Arnold ${ }^{1}$, K Mallawarachchi ${ }^{4}$ LS de Silva ${ }^{5}$ \\ ${ }^{1}$ Regional Directorate of Health Services, Colombo District, Sri Lanka; ${ }^{2}$ Department of Community Medicine, Faculty \\ of Medicine, University of Colombo. Sri Lanka; ${ }^{3}$ Department of Clinical Medicine, Faculty of Medicine, University \\ of Colombo, Sri Lanka; ${ }^{4}$ Ministry of Health, Sri Lanka; ${ }^{5}$ Postgradaute Institute of Medicine, University of Colombo, \\ Sri Lanka
}

"Correspondence: buddhikamaheshpk@gmail.com

DOI: https://doi.org/10.4038/jccpsl.v24i4.81418

Received on: 15 February 2018

Accepted on: 28 June 2018

\begin{abstract}
Indoor air pollution due to household cooking is a hidden public health problem especially in developing countries. This review article discusses global literature on the concepts on cleaner energy, effects of indoor air pollution due to cooking on the different aspects of the respiratory system and the potential way forward in dealing with them. We searched relevant articles published from year 2000 onwards in three electronic databases and in other publications using keywords. Two authors independently assessed the relevance of the articles based on the scope of review. Altogether, 56 articles and four webpages were cited. A narrative review was done.

Primitive fuels mentioned in the energy ladder are still commonly used for cooking, especially in the developing world. Around $40 \%$ of people worldwide suffer from energy poverty. The choice of fuel energy is decided by multi-faceted influences. Primitive fuels including bio-mass fuels yield more pollutants than cleaner fuels. Cooking practices have an influence on the amount of pollution. Higher prevalence of respiratory infections is associated with cooking smoke especially among children. Most documented literature points toward a higher prevalence of respiratory symptoms, lung cancer and impaired lung functions with cooking smoke. Cleaner fuels seemingly cause less pollution though the literature is rare on kerosene. In conclusion, energy poverty is expected to worsen in future. The associations between cooking smoke and negative respiratory consequences have been wellestablished in most research studies. Strategies of reducing household smoke due to cooking must be promoted.
\end{abstract}

\section{Introduction}

Indoor air pollution within households is one of the main contributors of mortality and disability globally (1). Emission due to household cooking fuels is found to be one of the main factors affecting indoor air pollution (2). Its adverse events may include communi- cable diseases, non-communicable diseases, growth retardation of children as well as negative effects on the foetus (1, 3-4). Around 3.8 million premature deaths that happen annually from non-communicable diseases are attributed to exposure to household air pollution from cooking with solid fuels (3). 
Respiratory system is the main system that is adversely affected by air pollution (5). Though much literature is available, many articles have been composed on fragmented areas in relation to the respiratory effects. This review article discusses documented global literature on the concepts on cleaner energy, effects of indoor cooking on the different aspects of the respiratory system and the potential way forward of dealing with them with special emphasis on the developing world.

\section{Methods}

Our literature search was done through PUBMED, GOOGLE SCHOLAR and MENDELEY databases. We explored the original research articles and reviews from year 2000 up to April 2017. The search terms included were: "biomass fuel AND indoor air pollution", "indoor air pollution AND respiratory symptoms", "air pollution AND cooking", "developing countries AND indoor air pollution" and "energy ladder". Furthermore, publi- cations of the World Health Organization and United Nations, and other related webpages were searched. Academic colleagues were consulted in tracing unpublished articles. Cross-referencing was done through references of the original articles.

The selection of publications was done in three rounds. In the first round, based on the abstracts or summaries, publications that were relevant to the scope of the present review were selected. By going through the selected publications, sub-titles for further review were determined. The second round of the selection process was done considering these sub-titles. In the third round, clarity of the conclusions was considered. Two authors independently assessed the relevance of the publications. When both agreed, the articles were selected; otherwise, the decision of another author was sought. Altogether 56 articles were selected and additionally four webpages were cited (Figure 1). A narrative review was done without pooled analysis.

No. of journal articles screened $=376$

No. of webpages screened $=15$

256 articles and 5 websites were not selected for further review.

No. of journal articles selected in the first
round = 120
No. of webpages selected in the first
round = 10

Figure 1. Flow diagram on the selection of publications 


\section{Results and Discussion}

\section{Cooking fuels and the energy ladder}

Cooking food is assumed to be of evolutionary significance to the human beings (9). It is believed that cooking would have increased the net energy intake from eating food (10). Even though literature is occasionally found on the disadvantages of cooking, more literature is in favour of the advantages of eating cooked food (10-12). In addition, home-based cooking has been found to be with many benefits compared to the consumption of eating out (13-15).

Many fuels have been used for indoor cooking in households. The traditional fuels include products of plants and animals, which include wood, animal dung, crop waste and coal. Out of these, the organic material which are derived from living organisms are termed as biomass fuel (16). The modern fuel methods include liquefied petroleum gas (LPG), kerosene, biogas, ethanol, gel-fuels, biodiesel and electricity (17).

The energy ladder model shows that household fuels can be grouped into three categories: primitive fuels, transition fuels and advanced fuels (18). The bio-mass fuels belong to the primitive fuel category, whereas kerosene, charcoal and coal belong to the transition fuel category. LPG, electricity and biogas are found in the advanced fuel category. It is assumed that with the improvement of the socio-economic status, households would shift upwards in the ladder (19). The fuels found higher up in the ladder produce less pollution per unit of fuel (20).

Energy poverty is defined as "the absence of sufficient choice in accessing adequate, affordable, reliable, high-quality, safe and environmentally benign energy services to support economic and human development" (21). Since the bio-mass fuels are assumed to be producing more pollutants, households using them as prime domestic fuel are suffering from energy poverty. The energy poverty is worse in developing countries and expected to be worse in the coming years $(17,22)$. It has been estimated that two out of five people in developing countries suffer from energy poverty (23). The statistics of World Health Organization (WHO) summarizes that around the world, about three billion people cook using burning bio-mass (wood, animal dung and crop waste) and coal (3).

\section{Factors affecting the choice of energy}

In a research done in Sri Lanka, factors impeding the transition to cleaner fuels were explored. It concluded that not having enough motivation for switching over, lack of better technology options, financial risks and financing related reasons as the impeding factors (24). The way people make choices on fuel is not simple to explain. Many households use multiple fuel sources (25-26). Furthermore, they may revert back to a previous method (24). Many positive and negative factors have been identified to influence the decision of energy source for cooking. Those include characteristics of householders, income level, food preferences, access to fuel, fuel prices and cultural aspects (27-31). The direction of factors mentioned in the literature varies according to the context. However, income related factors are given priority in the analysis of many of the studies. Furthermore, the associated factors have different impacts on the choice process at different settings (19).

\section{Air pollutants through cooking}

In most parts of the developing world, traditional devices are used for cooking. The incomplete combustion of these give rise to many pollutants including carbon monoxide, aldehydes, nitrogen oxides, polycyclic aromatic hydrocarbons, etc. (32-33). Indoor cooking is also a primary source of particle pollution, which is also called 'particulate matter' (PM). This consists of solid and liquid particles in the air (7). In a study on PM, it was found that $29-48 \%$ of sourcewise attribution was from solid fuels (2). An Indian study revealed that $50-80 \%$ of the total suspended particulate emissions of cooking stoves using biomass and coal, were respirable being less than $2 \mu \mathrm{m}$ in size (34). According to a Chinese study, PM levels during winter were significantly correlated with the usage of solid fuel (35).

Incomplete combustion is influenced by poor ventilation and the poor quality of cooking devices used in lower-income countries (6). Improved cooking devices are associated with less pollution. Furthermore, factors such as higher education is associated with the usage of improved cooking devices than traditional ones (36). In return, negative respiratory effects are less when improved cooking devices are used (37). 


\section{Respiratory infections}

Respiratory infections are associated with biomass fuel consumption (38). It is mentioned that more than one tenth of the deaths attributed to household air pollution caused by solid fuels is due to pneumonia (3). A study had been done in rural Kenya to explore the respiratory association of particulates $<10 \mu \mathrm{m}$ diameter generated from bio-mass fuels. It concluded that respiratory infections including acute lower respiratory tract infections have significant associations with this exposure (39). The burden of these infections is higher among children, as explained by many pathophysiological elaborations (40). The high inspiration rates, not well-developed epithelium and immune systems, narrow airways and spending more time at home at cooking times are some of the hypotheses for this (41-42).

Being exposed to polluted air within households almost doubles the likelihood of getting childhood pneumonia (3). Particulate matter due to household solid fuels is responsible for more than half of the mortality due to lower respiratory infections among children less than five years (3). In a follow-up study of a cohort of new-borns in India, it was documented that exposure to bio-mass fuel is associated with $34 \%$ excess risk of getting respiratory illnesses (4).

\section{Impaired lung functions}

Negative effects of household cooking on the lung functions have been documented (43). In a study done in Cameroon, using wood as a fuel was found to be a significant risk factor for lung function impairment in addition to the other factors such as chronic bronchitis, height and age (44). In a study done in Ecuador, it was concluded after the multivariate analysis that the children exposed to bio-mass fuel within households had reduced forced vital capacity and forced expiratory volume in one second (45). Yet, in the same study, a significant difference was not detected between the pulmonary functions and fuel category among women. An increase in lung functions following the reduction of PM has been documented in more global literature (46). Contradictory evidence was found based on a Nigerian study, in which airway obstruction was not reported to be an effect due to firewood consumption $(\mathrm{p}=0.41)$ (47). Significantly improved lung functions were not observed following 12-18 months of indoor air pollution reduction in an experimental study done in Guatemala, though there was a significant reduction of respiratory symptoms (48). Higher lung functions among smoke-exposed women were observed in another group of women in Guatemala (49).

\section{Effects on wheezing, asthma and chronic obstructive pulmonary disease (COPD)}

A cross-sectional study has been done in Columbia to describe the risk factors of asthma and wheezing among adults. Following the logistic regression analysis, the study concluded indoor wood smoke exposure as a risk factor along with other factors such as occupational exposure to dust particles, gases or fumes (50). Longer exposure to wood smoke $(\mathrm{p}=0.04)$ was found to be a risk factor for getting COPD among females in Brazil. Respiratory symptoms were commoner in this group with COPD. Even among the women in whom COPD was not diagnosed, there was a higher prevalence of respiratory symptoms $(\mathrm{p}<0.001)$ (51). In a study done in Venezuela, it was reported that wood smoke is a risk factor for asthma among children compared to cooking with gas (adjusted odds ratio $(\mathrm{aOR})=2.12 ; 95 \%$ confidence interval $(\mathrm{CI})=1.18$, 3.84) (52). Studies done in Sri Lanka too point towards the indoor cooking smoke causing respiratory symptoms among children (53-54).

A negative association was observed in a Nigerian study done on 299 village children. The study concluded that using firewood daily did not significantly increase the likelihood of getting asthma-related symptoms $(\mathrm{OR}=2.36 ; 95 \% \mathrm{CI}=0.66,8.44)$ (47). A German study done among 5078 children explored the association between asthma and cooking with LP gas. With logistic and multinomial regression, asthma and wheezing were not found to have significant associations with gas cooking. However, a positive association $(\mathrm{p}<0.05)$ was observed between exposure to gas cooking and the exposure to other indoor factors such as dampness, tobacco smoke and pets. It was highlighted that in assessing the effects of gas cooking, the other indoor factors must be considered (55).

\section{Cancer}

A case-control study was done in China to determine the association between PM and the occurrence of lung cancer among non-smoking women. It was found that the solid fuel usage for cooking $(\mathrm{aOR}=4.08)$ and higher frequency of cooking $(\mathrm{aOR}=3.30)$ were risk factors for lung cancer. The PM (1) level among 
cases was three times higher than in controls (35). In an Indian study following multivariate analysis, it was found that bio-mass fuel exposure was a significant risk factor $(\mathrm{OR}=3.59 ; 95 \% \mathrm{CI}=1.07,11.97)$ after adjusting for smoking (56). This association between the indoor cooking fuels and lung cancer was further proven by a meta-analysis done in China (57).

\section{Comparison of the ends of energy ladder}

In a cross-sectional study done in Nepal, it was found that the average smoke level (PM10) in kitchens was three times higher when using bio-mass fuels compared to cleaner fuels (kerosene, LPG, bio-gas). Bio-mass smoke was significantly associated with more respiratory disorders than cleaner fuels (58). In a study done in India comparing the effects of wood, cattle dung, coal and kerosene, LPG was regarded as the control group. The ill effects of using bio-mass as the prime domestic fuel were highlighted (34). Kerosene is traditionally considered as a safer fuel than bio-mass fuels. There is a scarcity of the literature on its usage as a fuel for cooking. Despite discrepancies in the findings, there is a potential that it may cause respiratory infections including tuberculosis, asthma, cancer and other negative effects (59).

\section{The way forward}

Improved access and correct use of cooking fuels would have contributed to achieving the Millennium Development Goals (6). The importance of selecting a safe energy source at household level has been even highlighted in the Sustainable Developmental Goals (8). Currently, air pollution including its indoor domain has been a neglected public health issue in many developing countries (60). Policy decisions on incorporating financing with energy governance have been identified as vital in the advancement (24).

Several studies have documented the novel techniques including the introduction of modified cooking devices in Asian region (23, 32). Furthermore, a research done in five countries has concluded that there are non-plantation bio-mass products such as municipal waste and industrial waste water which can be used as energy sources. Also, it has suggested the replacement of fuel wood with mechanisms such as LPG. The potential fuel wood savings with modification of the energy appliances of the total non-plantation biomass had been noted as $24 \%$ and $35 \%$ of energy in Philippines and Sri Lanka, respectively (16).
The strategies which can be adopted in minimizing the smoke are highlighted under three categories by WHO namely changing the source of pollution, improving the living environment and modifying user behaviour (6). Improving the devices used for cooking, using better fuel-cooker combinations and reducing the need for fire are grouped under the first category. Ventilation improvements and designing the kitchen and stove placement are mentioned under the second category. Changing cooking practices and avoiding smoke are mentioned under the third category (6). Hence, it is essential that the low- and middle-income countries seek the possibility of reducing the indoor air pollution due to cooking.

One limitation of this review is being a narrativereview without quantification of the effects. Yet, it covers a comprehensive scope addressing all aspects of respiratory effects due to indoor cooking including the way forward.

\section{Conclusions}

Bio-mass fuels are found in the primitive category of the energy ladder. Energy poverty is commonly found in developing countries and expected to become worse in the coming years. The associations between cooking smoke and negative respiratory consequences have been well-established in most research studies with the exceptions of only a few. Initiatives on the reduction of household smoke and promotion of cleaner energy are essential in achieving the expected global targets such as Sustainable Developmental Goals.

\section{Author Declarations}

Competing interests: The authors declare that they have no competing interests.

Funding: Self-funded.

Acknowledgement: Not applicable

Author contribution: All authors (PKB, MW, S, SM, $\mathrm{KM}$ and $\mathrm{SD}$ ) were involved in the planning of the review. All authors were involved in literature search and synthesis of findings. PKB typed the initial draft of the review. All others proof-read and modified the article. All authors went through the final article. 


\section{References}

1. Weinstein JR, Asteria-Peñaloza R, Diaz-Artiga A, Davila G, Hammond SK, Ryde IT, et al. Exposure to polycyclic aromatic hydrocarbons and volatile organic compounds among recently pregnant rural Guatemalan women cooking and heating with solid fuels. International Journal of Hygiene and Environmental Health 2017; 220(4): 726-735.

2. Secrest MH, Schauer JJ, Carter E, Baumgartner J. Particulate matter chemical component concentrations and sources in settings of household solid fuel use. Indoor Air 2017; 27(6).

3. WHO. Household air pollution and health. Media center: World Health Organization, 2016.

Available from: http://www.who.int/mediacentre/ factsheets/fs292/en/

4. Tielsch JM, Katz J, Thulasiraj RD, Coles CL, Sheeladevi S, Yanik EL, Rahmathullah L. Exposure to indoor biomass fuel and tobacco smoke and risk of adverse reproductive outcomes, mortality, respiratory morbidity and growth among newborn infants in south India. International Journal of Epidemiology 2009; 38(5): 1351-1363.

5. Nandasena S, Wickremasinghe AR, Sathiakumar N. Indoor air pollution and respiratory health of children in the developing world. World Journal of Clinical Pediatrics 2013; 2(2): 6-15.

6. WHO. Fuel for life/ : household energy and health. World Health Organization, 2006 [Internet].

Available from: http://www.who.int/indoorair/ publications/fuelforlife/en/

7. CDC. Air quality: particle pollution. Centre for Disease Control and Prevention, 2016 [Internet].

Available from: https://www.cdc.gov/air/particulate_ matter.html

8. UN. Sustainable Development Goals. United Nations, 2015 [Internet].

Available from: https://sustainabledevelopment. un.org/?menu $=1300$

9. Carmody RN \& Wrangham RW. The energetic significance of cooking. Journal of Human Evolution 2009; 57(4): 379-391.

10. Boback SM, Cox CL, Ott BD, Carmody R, Wrangham RW, Secor SM. Cooking and grinding reduces the cost of meat digestion. Comparative Biochemistry and Physiology Part A: Molecular \& Integrative Physiology 2007; 148(3): 651-656.

11. Gerber N, Scheeder MRL, Wenk C. The influence of cooking and fat trimming on the actual nutrient intake from meat. Meat Science 2009; 81(1): 148-154.

12. Groopman EE, Carmody RN, Wrangham RW. Cooking increases net energy gain from a lipid-rich food.
American Journal of Physical Anthropology 2015; 156(1): 11-18.

13. Lobato JCP, Costa AJL, Sichieri R. Food intake and prevalence of obesity in Brazil: an ecological analysis. Public Health Nutrition 2009; 12(11): 2209-2215.

14. Beydoun MA, Powell LM, Wang Y. Reduced awayfrom-home food expenditure and better nutrition knowledge and belief can improve quality of dietary intake among US adults. Public Health Nutrition 2009; 12(3): 369-381.

15. Kramer RF, Coutinho AJ, Vaeth E, Christiansen K, Suratkar S, Gittelsohn J. Healthier home food preparation methods and youth and caregiver psychosocial factors are associated with lower BMI in African American youth. The Journal of Nutrition 2012; 142(5): 948-954.

16. Bhattacharya SC, Abdul Salam P, Runqing H, Somashekar HI, Racelis DA, Rathnasiri PG, et al. An assessment of the potential for non-plantation biomass resources in selected Asian countries for 2010. Biomass and Bioenergy 2005; 29(3): 153-166.

17. Foell W, Pachauri S, Spreng D, Zerriffi H. Household cooking fuels and technologies in developing economies. Energy Policy 2011; 39(12): 7487-7496.

18. Heltberg R. Fuel switching: evidence from eight developing countries. Energy Economics 2004; 26(5): 869-887.

19. van der Kroon B, Brouwer R, van Beukering PJH. The energy ladder: theoretical myth or empirical truth? Results from a meta-analysis. Renewable and Sustainable Energy Reviews 2013; 20: 504-513.

20. Masera OR, Saatkamp BD, Kammen DM. From linear fuel switching to multiple cooking strategies: a critique and alternative to the energy ladder model. World Development 2000; 28(12): 2083-2103.

21. González-Eguino M. Energy poverty: an overview. Renewable and Sustainable Energy Reviews 2015; 47: 377-385.

22. Elledge MF, Phillips MJ, Thornburg VE, Everett KH, Nandasena S. A profile of biomass stove use in Sri Lanka. International Journal of Environmental Research in Public Health 2012; 9(12): 1097-1110.

23. Chowdhury MSH, Koike M, Akther S, Miah D. Biomass fuel use, burning technique and reasons for the denial of improved cooking stoves by Forest User Groups of Rema-Kalenga Wildlife Sanctuary, Bangladesh. International Journal of Sustainable Development \& World Ecology 2011; 18(1): 88-97.

24. Wickramasinghe A. Energy access and transition to cleaner cooking fuels and technologies in Sri Lanka: issues and policy limitations. Energy Policy 2011; 39(12): 7567-7574. 
25. Cooke P, Köhlin G, Hyde WF. Fuelwood, forests and community management - evidence from household studies. Environment and Development Economics 2008; 13(1): 103-135.

26. Martins J. The impact of the use of energy sources on the quality of life of poor communities. Social Indicators Research 2005; 72(3): 373-402.

27. Heltberg R. Factors determining household fuel choice in Guatemala. Environment and Development Economics 2005; 10(3): 337-361.

28. Narasimha Rao M, Reddy BS. Variations in energy use by Indian households: an analysis of micro level data. Energy 2007; 32(2): 143-153.

29. Ekholm T, Krey V, Pachauri S, Riahi K. Determinants of household energy consumption in India. Energy Policy 2010; 38(10): 5696-5707.

30. Ouedraogo B. Household energy preferences for cooking in urban Ouagadougou, Burkina Faso. Energy Policy 2006; 34(18): 3787-3795.

31. Alem Y, Beyene AD, Kohlin G, Mekonnen A. Modeling household cooking fuel choice: A panel multinomial logit approach. Energy Economics 2016; 59: 129-137.

32. Panwar NL, Kurchania AK, Rathore NS. Mitigation of greenhouse gases by adoption of improved biomass cookstoves. Mitigation and Adaptation Strategies for Global Change 2009; 14(6): 569-578.

33. Bhattacharya SC, Abdul Salam P, Sharma M. Emissions from biomass energy use in some selected Asian countries. Energy 2000; 25(2): 169-188.

34. Raiyani C V, Shah SH, Desai NM, Venkaiah K, Patel JS, Parikh DJ, Kashyap SK. Characterization and problems of indoor pollution due to cooking stove smoke. Atmospheric Environment. Part A. General Topics 1993; 27(11): 1643-1655.

35. Mu L, Liu L, Niu R, Zhao B, Shi J, Li Y, et al. Indoor air pollution and risk of lung cancer among Chinese female non-smokers. Cancer Causes \& Control 2013; 24(3): 439-450.

36. Chartier R, Phillips M, Mosquin P, Elledge M, Bronstein K, Nandasena S, et al. A comparative study of human exposures to household air pollution from commonly used cookstoves in Sri Lanka. Indoor Air 2017; 27(1): 147-159.

37. Phillips M, Smith E, Mosquin P, Chartier R, Nandasena $\mathrm{S}$, Bronstein $\mathrm{K}$, et al. Sri Lanka pilot study to examine respiratory health effects and personal PM2.5 exposures from cooking indoors. International Journal of Environmental Research and Public Health 2016; 13(8): 791.

38. Zhang J. Indoor air pollution: a global health concern. British Medical Bulletin 2003; 68(1): 209-225.
39. Ezzati M \& Kammen DM. Quantifying the effects of exposure to indoor air pollution from biomass combustion on acute respiratory infections in developing countries. Environmental Health Perspectives 2001; 109(5): 481-488.

40. Barnes B. Behavioural change, indoor air pollution and child respiratory health in developing countries: a review. International Journal of Environmental Research and Public Health 2014; 11(5): 4607-4618.

41. Moya J, Bearer CF, Etzel RA. Children's behavior and physiology and how it affects exposure to environmental contaminants. Pediatrics 2004; 113(4 Suppl): 996-1006.

42. Barnes B, Mathee A, Moiloa K. Assessing child time - activity patterns in relation to indoor cooking fires in developing countries: a methodological comparison. International Journal of Hygiene and Environmental Health 2005; 208(3): 219-225.

43. Fullerton DG, Bruce N, Gordon SB. Indoor air pollution from biomass fuel smoke is a major health concern in the developing world. Tropical Medicine \& Hygiene 2008; 102(9): 843-851.

44. Ngahane BHM, Ze EA, Chebu C, Mapoure NY, Temfack E, Nganda M, et al. Effects of cooking fuel smoke on respiratory symptoms and lung function in semi-rural women in Cameroon. International Journal of Occupational and Environmental Health 2015;21(1): 61-65.

45. Rinne ST, Rodas EJ, Bender BS, Rinne ML, Simpson JM, Galer-Unti R, Glickman LT. Relationship of pulmonary function among women and children to indoor air pollution from biomass use in rural Ecuador. Respiratory Medicine 2006; 100(7): 1208-1215.

46. Boogaard H, Fischer PH, Janssen NAH, Kos GPA, Weijers EP, Cassee FR, et al. Respiratory effects of a reduction in outdoor air pollution concentrations. Epidemiology 2013; 24(5): 753-761.

47. Thacher JD, Emmelin A, Madaki AJK, Thacher TD. Biomass fuel use and the risk of asthma in Nigerian children. Respiratory Medicine 2013; 107(12): 18451851.

48. Díaz E, Smith-Sivertsen T, Pope D, Lie RT, Díaz A, McCracken $\mathrm{J}$, et al. Effect of reducing indoor air pollution on women's respiratory symptoms and lung function: the RESPIRE randomized trial, Guatemala. Americal Journal of Epidemiology 2009; 170(2): 211-220.

49. Díaz E, Bruce N, Pope D, Lie RT, Díaz A, Arana B, et al. Lung function and symptoms among indigenous Mayan women exposed to high levels of indoor air pollution. International Journal of Tuberculosis and Lung Disease 2007; 11(12): 1372-1379. 
50. Gonzalez-Garcia M, Caballero A, Jaramillo C, Maldonado D, Torres-Duque CA. Prevalence, risk factors and underdiagnosis of asthma and wheezing in adults 40 years and older: a population-based study. Journal of Asthma 2015; 52(8): 823-830.

51. Moreira MAC, Barbosa MA, Jardim JR, Queiroz MCC, Inácio LU. Chronic obstructive pulmonary disease in women exposed to wood stove smoke. Revista da Associação Médica Brasileira (RAMB) 2012; 59(6): 607-613.

52. Kraai S, Verhagen LM, Valladares E, Goecke J, Rasquin L, Colmenares P, et al. High prevalence of asthma symptoms in Warao Amerindian children in Venezuela is significantly associated with open-fire cooking: a cross-sectional observational study. Respiratory Research 2013; 14(1): 76.

53. Nandasena S, Wickremasinghe AR, Sathiakumar N. Respiratory health status of children from two different air pollution exposure settings of Sri Lanka: a cross-sectional study. American Journal of Industrial Medicine 2012; 55(12): 1137-1145.

54. Lankathilaka KN, Seneviratne RDA, Fernando DN. Indoor air quality and respiratory symptoms among children and women. Sri Lanka Association for the Advancement of Science (SLAAS), 56 ${ }^{\text {th }}$ Annual Sessions, Volume Part-1 Abstract, 2000.
55. Casas L, Tischer C, Tiesler C, Brüske I, Koletzko S, Bauer CP, et al. Association of gas cooking with children's respiratory health: results from GINIplus and LISAplus birth cohort studies. Indoor Air 2012; 22(6): 476-482.

56. Behera D, Balamugesh T. Indoor air pollution as a risk factor for lung cancer in women. Journal of the Association of Physicians of India 2005; 53: 190-192.

57. Zhao Y, Wang S, Aunan K, Martin Seip H, Hao J. Air pollution and lung cancer risks in China - a metaanalysis. Science of the Total Environment 2006; 366(2-3): 500-513.

58. Shrestha IL \& Shrestha SL. Indoor air pollution from biomass fuels and respiratory health of the exposed population in Nepalese households. International Journal of Occupational and Environmental Health 2005; 11(2): 150-160.

59. Epstein MB, Bates MN, Arora NK, Balakrishnan K, Jack DW, Smith KR. Household fuels, low birth weight, and neonatal death in India: the separate impacts of biomass, kerosene, and coal. International Journal of Hygiene and Environmental Health 2013; 216(5): 523-532.

60. Nandasena YLS, Wickremasinghe AR, Sathiakumar N. Air pollution and health in Sri Lanka: a review of epidemiologic studies. BMC Public Health 2010; 10(1): 300 . 